\title{
Ultrasonic Intensification of Diesel Fuel Desulfurization: Review
}

\author{
Akhmadova Kh.Kh. \\ Department of Chemical technology of oil and gas \\ Grozny State Oil Technical University named after acad. \\ M.D. Millionshchikov \\ Grozny, Russia \\ hava9550@mail.ru \\ Pimenov A.A. \\ Department of Organic Chemistry \\ Samara State Technical University \\ Samara, Russian \\ dpimenov@yandex.com \\ Abdulmezhidova Z.A. \\ Department of Chemical technology of oil and gas \\ Grozny State Oil Technical University named after acad. \\ M.D. Millionshchikov \\ Grozny, Russia \\ zuli20@mail.ru
}

Musaeva M.A.

Department of Chemical technology of oil and gas Grozny State Oil Technical University named after acad. M.D. Millionshchikov
Grozny, Russia
milanama95@mail.ru

Abstract - The article shows that nowadays the strict requirements are being applied to the quality of diesel fuel (DF), especially to the content of organic sulfur compounds. These requirements must comply with European standards. Desulfurization of diesel fuels is carried out by different methods with the use of both classical technologies and non-traditional ones. One of the methods for the intensification of desulfurization is an ultrasonic treatment method, whose results used for desulfurization of diesel fuel are considered in this article.

Keywords-diesel fuel, desulfurization, ultrasonic exposure, non-traditional desulfurization methods, cavitating, sulfones

\section{INTRODUCTION}

Due to the fact that in recent years there has been a tendency to increase the consumption of diesel fuel (DF) throughout the world with the concurrent toughening of environmental requirements to its quality [1], the modern global market places high demands on the content of organic sulfur compounds in diesel fuels [2-4].

\author{
Makhmudova L.Sh. \\ Department of Chemical technology of oil and gas \\ Grozny State Oil Technical University named after acad. \\ M.D. Millionshchikov \\ Grozny, Russia \\ mls66@mail.ru
}

Khadisova Z.T.

Department of Chemical technology of oil and gas Grozny State Oil Technical University named after acad. M.D. Millionshchikov

Grozny, Russia

janna h@list.ru

Takayeva M.A.

Department of Chemical technology of oil and gas Grozny State Oil Technical University named after acad. M.D. Millionshchikov

Grozny, Russia

karina-lada@mail.ru

\section{Sadulaeva A.S.}

Department of Chemical technology of oil and gas Grozny State Oil Technical University named after acad. M.D. Millionshchikov Grozny, Russia

Albina_sadulaeva@mail.ru

With the objective to reduce the harmful effects of sulfur on the environment and human health, most countries are more and more strictly regulating its content in diesel fuel every year.

The maximum sulfur content in automotive diesel fuel was reduced from $0.2-0.5 \% \mathrm{wt}$. in the $1980 \mathrm{~s}$ to $15 \mathrm{ppm}$ in the USA in 2006 and up to $10 \mathrm{ppm}$ in 2010 in European countries [5].

Starting from January 1, 2011, the Russian Federation also limited the sulfur content, but to the level of $350 \mathrm{ppm}$, which corresponds to the Euro-3 standard.

Euro-4 standards allow the content of organic sulfur compounds to be not more than $50 \mathrm{ppm}$, and according to the Euro 5 standard it is $10 \mathrm{ppm}$. [6]. In the most developed countries like the USA, Japan and the countries of the EU, the permissible sulfur content in fuel is currently $10 \mathrm{ppm}$ [4].

In Russia, oil companies are doing a lot of work aimed at the massive adoption of domestic refineries in the production 
of environmentally friendly diesel fuel with a sulfur content of no more than $0.035 \%$ and $0.005 \%$ and with the content of polycyclic aromatic hydrocarbons not more than $11 \%$ [1].

Since 2016 all diesel fuel in Russia have begun to be produced in accordance with the European standards, namely: more than $50 \%$ of diesel fuel produced in the country meet the requirements of Euro-3 standards (350 ppm sulfur content), Euro-4 (50 ppm sulfur content) and Euro -5 (10 ppm sulfur content) [7].

The classical method of removing sulfur from diesel fuel is the process of catalytic hydrodesulfurization performed at $350-450^{\circ} \mathrm{C}$ and at a hydrogen pressure of $3 \mathrm{MPa}$ with $\mathrm{Co}-\mathrm{Mo}$ or Ni-Mo catalysts supported on alumina [4].

Despite the fact that catalytic desulfurization hydroprocesses are widely used and are the main processes of desulfurization, they have a number of significant drawbacks being as follows: tough operating conditions, high operating costs, low utilization of raw materials and inability to satisfy all the tougher environmental standards for sulfur [14]. The reduction of sulfur in petroleum products up to $50 \mathrm{ppm}$ and below by hydrofining processes requires large expenses.

Application of this technology enables to reduce sulfur content in the fuel to $300-500 \mathrm{ppm}$. It is necessary to apply another type of technologies being hydrogenless with the objective to gain the deeper purification to a degree of desulfurization equal to $97-99 \%$ (requirements of the EU and US standards). These technologies either individually or in combination with classical technologies enable to intensify desulfurization of motor fuels with regards to the requirements of European standards.

Therefore, the search for new unconventional methods for the removal of sulfur from motor fuels is highly relevant at present. The most intensive research in the sphere of nontraditional methods for diesel fuels desulphurization is carried out in the field of technologies based on the use of oxidative desulfurization, bio-desulfurization, ozonation, selective adsorption, ultrasonic treatment [8].

The most available and promising methods for isolating organic sulfur compounds are oxidative desulfurization ones, which apply various oxidizing agents, catalysts of extractants [4].

Oxidative desulfurization can be carried out at room temperature and atmospheric pressure, which can significantly reduce the cost of the process. During desulfurization sulfur compounds are oxidized to sulfones and sulphooxides, which are then easily removed by conventional separation methods, since their properties are significantly different from the properties of petroleum hydrocarbons that form the basis of fuels [9].

The extractants like methyl alcohol, ethylene glycol monoesters or aqueous acetone can be used for the removal of sulfoxides and sulfones formed during oxidative desulfurization.

In this case, oxidative desulfurization is more economical while the cheapest oxidizers being air oxygen, hydrogen peroxide, organic peroxides and others are used [10].
The outcomes of a significant amount of research devoted to the problem of DF desulphurization are partially reflected in review articles and thesis researches having been published since the 2000s [1, 2, 4, 11-24].

One of the main lines of research, which is currently of great priority, is the intensification of diesel fuels desulfurization.

Numerous studies show that the intensification of diesel fuels desulfurization is achieved by using unconventional methods, and ultrasonic treatment is the most effective of them $[4,23-61]$.

\section{ULTRASONIC INTENSIFICATION OF DIESEL FUEL DESULFURIZATION}

The study of processes and the experimental application of ultrasonic processing in various technological processes of oil refining began in the 1980s [25].

The interest in the ultrasonic treatment of hydrocarbons is primarily due to the potential of various refining processes at relatively low average temperatures and pressures compared to similar parameters of traditional refining technologies [28, 29], as well as a significant improvement in the properties of petroleum under the influence of ultrasound [5, 21, 22].

Currently, ultrasound is widely used in various processes of oil refining and oil production. Thus, attempts are being made to experimentally and practically apply high-intensity ultrasonic vibrations in thermomechanical action on oil (to initiate low-temperature cracking under conditions of cavitation and ultrasonic vibrations without using catalysts [26-29]), decontamination of sludge deposits [30], separation of water from oil in preparation of commercial products [31], reduction of the oil viscosity during transportation [32,33], intensification of numerous operations in oil production [25], etc.

The uniqueness and effectiveness of ultrasonic exposure is caused by the phenomenon of cavitation, which is the effective means of concentrating the energy of a low-density ultrasonic wave into a high energy density associated with pulsations and collapse of cavitation bubbles in the liquid phase [34].

Analysis of the use of ultrasonic treatment with the objective to intensify the desulfurization of petroleum products by means of various methods enables to draw conclusions about the prospects of using ultrasound to clean oil and petroleum products from organic sulfur compounds.

Studies [35] consider the effect of complex ultrasonic treatment of raw materials and catalysts in the hydrotreatment of the diesel fraction for the production of environmentally friendly diesel fuel. For this purpose, an ultrasonic activation unit for raw materials and an industrial catalyst was created and tested as part of a hydrotreatment unit for desulfurization of a straight-run diesel fraction.

According to the results of research [35], industrial tests were conducted on the basis of the pilot plant of All-Russian Scientific Research Institute for Oil Refining and proposed 
technical solutions for upgrading the catalytic hydrotreating technology of the diesel fraction by means of its preliminary ultrasonic activation.

The pretreatment of a straight-run diesel fraction by ultrasound exposure, carried out on a designed pilot plant, showed an activating effect of ultrasound on organic sulfur compounds contained in it, which contributed to an increase in the depth of sulfur removal during subsequent catalytic hydrodesulfurization of the diesel fraction.

At the industrial hydrotreating unit of the diesel fraction under the conditions of temperature equal to $360^{\circ} \mathrm{C}$, a pressure of $3 \mathrm{MPa}$, a volumetric feed rate of $3 \mathrm{~h}-1$ with preliminary ultrasonic activation, the desulfurization reached $97.0 \%$, and when being hydrotreated without activation, it reached $96.4 \%$.

The results of ultrasonic intensification of the catalytic oxidative desulfurization of straight-run diesel fraction are given and the process and technological parameters of the process are determined in [36].

The studies $[35,36]$ show that ultrasonic exposure increases the degree of cleaning from organic sulfur compounds by about 2 times, thus eliminating the need for additional heating and increasing the pressure in the reaction chamber.

The outcomes of experiments on the desulfurization of diesel fractions from organic sulfur compounds using various methods indicated the effectiveness of ultrasonic treatment, the most efficient of which was the least energy-intensive method of preliminary ultrasonic activation of the catalyst during $30 \mathrm{sec}$.

In recent years, especially foreign countries pay considerable attention to the oxidative desulfurization of diesel fuels with the application of hydrogen peroxide and various catalysts as an oxidative system.

According to the author [21,22], ultrasonic exposure is rather promising in the process of selective oxidation of DF organic compounds by hydrogen peroxide due to intensive heat and mass transfer and minimizing the residence time of the raw material in the reaction zone.

Basing on laboratory experiments it was shown in [6] that this method can be significantly intensified due to ultrasonic treatment. A straight-run diesel fraction selected in the production of Gazprom neftekhim Salavat (with viscosity equal to $2.50 \mathrm{cSt}$, density $0.88 \mathrm{~g} / \mathrm{cm} 3$, sulfur content $0.94 \%$ by weight) was used for the study of ultrasonic treatment. A $35 \%$ hydrogen peroxide $\left(\mathrm{H}_{2} \mathrm{O}_{2}\right)$ was used as an oxidizing agent, the industrial catalyst $\mathrm{KT}-40$ and iron chloride $\mathrm{FeCl}_{3}$, ammonium tungstate $5\left(\mathrm{NH}_{4}\right)_{2} \mathrm{O}: 12 \mathrm{WO}_{3} \mathrm{H}_{2} \mathrm{O}$, and distilled water effective in such cases were applied as catalysts.

A series of experiments were carried out with the objective to select rational modes of oxidation for the organic sulfur compounds of the diesel fraction in [6]. These experiments varied the types of catalyst, the amount of oxidizer, the intensity and time of ultrasonic exposure varied.

The studies devoted to determining the activity of catalysts with the application of $35 \%$ hydrogen peroxide indicated the highest activity of ammonium tungstate. The degree of purification from organic sulfur compounds using this catalyst was equal to $29.1 \%$.

The efficiency of desulfurizing straight-run diesel fraction with the use of ammonium tungstate as a catalyst significantly increased in accordance with the amount of hydrogen peroxide $(2-7 \%)$ when using ultrasonic treatment. The degree of purification from sulfur compounds increased by $50 \%$.

The study of the intensity of ultrasound exposure within the range of $10-25 \mathrm{~W} / \mathrm{cm} 2$, and the processing time equal to 2 8 minutes enabled to establish a rational oxidation mode achieved at an intensity of ultrasound exposure equal to 20 $\mathrm{W} / \mathrm{cm} 2$ during 4 minutes.

The energy consumption for ultrasonic treatment is very high under the conditions of desulfurizing diesel fuel in an industrial environment. In this case, it is advisable to preactivate the catalyst in an ultrasonic field and then feed it into the reaction chamber with a mixer [6]. The outcomes of a comparative experiment on diesel fuel desulfurization from organic sulfur compounds (implemented with the application of various methods for 4 minutes) showed the effectiveness of this solution. The degree of cleaning from sulfur-containing compounds was $19.2 \%$ without ultrasonic treatment, mixing of reaction mixture with catalyst pre-activation during 1 min was $25.3 \%$ and the ultrasonic treatment of the reaction mixture without stirring was $28.9 \%$.

Sulphco has developed the process of oxidizing water-fuel emulsion with hydrogen peroxide under ultrasonic exposure over a catalyst at $70-80^{\circ} \mathrm{C}$ and atmospheric pressure in an ultrasonic reactor with the objective to reduce the sulfur content in diesel fuel [37-38].

In one minute the sulfur content in diesel fuel was reduced from 550 to $10 \mathrm{ppm}$. According to company estimates, the process was cheaper than hydrotreating. The disadvantage of this method was the need for the subsequent extraction of organic sulfur compounds from the purified organic phase, which in its turn led to additional expenditure of reagents and budget.

This is confirmed by the study [35], which shows that ultrasound exposure is rather promising in selective oxidation of diesel fuel organic compounds by hydrogen peroxide due to the intensive heat and mass transfer, minimizing the residence time of the raw material in the reaction zone.

Studies [39-50] show that the use of ultrasound in the liquid-phase oxidation of organic compounds increases the rate of initiation and oxidation.

It was shown in [45] that the oxidation rate of organic compounds of middle distillate oil fractions increases when using hydrogen peroxide and acetone under the influence of an ultrasonic field. The efficiency of hydrotreatment increases under the influence of ultrasound and the sulfur content drops from 1.78 to $1.34 \%$.

The studies [4, 46-51] found that organic sulfur compounds can be removed from the fuels of various origins (including those of oil origin) by the method in which oxidative desulfurization is combined with ultrasound. 
Ultrasonic treatment allows reducing the reaction time of sulfur components with an oxidizing agent up to the level of several minutes [52]

The work [53] describes the continuous method of oxidative desulfurization of petroleum products under ultrasonic action.

Diesel fuel is mixed with water, hydroperoxide and aliphatic hydrocarbons $\mathrm{C}_{15}-\mathrm{C}_{20}$ and the resulting multiphase reaction medium is continuously treated by ultrasound in a flow-through mode. This method enables significant reduction of the amount of organic sulfur compounds in the final product.

Ultrasonic treatment of the diesel fraction in the presence of hydrogen peroxide aqueous solution and a quaternary ammonium salt as an interfacial catalyst reduces the sulfur content in the fuel to less than $0.25 \%[54,55]$.

The side formation of 2- and 3-benzothiophenesulfones can be avoided using a fluorine-containing phase transfer catalyst [54].

The following three layers: oxidized diesel fuel (upper layer), residue (lower layer) and aqueous layer (middle) are formed under the conditions of ultrasonic processing of diesel fuel in the presence of an aqueous solution of hydrogen peroxide. The residue is less than $1 \%$ of the total fuel and it contains about $2 \%$ sulfur [55].

The review article $[4,56,57]$ states that sulfur recovery efficiency does not exceed $66 \%$ per 2.5 hours under the conditions of oxidative desulfurization of the diesel fraction. The combination of ultrasonic treatment with oxidative desulfurization enables to obtain the sulfur removal degree equal to $99 \%$ during a few minutes with the $87 \%$ yield of refined fuel [55].

The effect of the Fenton agent and ultrasound on the degree of desulfurization of diesel fuel was investigated in [58].

The authors found that adding Fenton-agent to the hydrogen peroxide or acetic acid system increases the efficiency of desulfurization, and ultrasonic treatment in the process of desulfurization gives a synergistic effect $[23,58]$.

Under the most favorable conditions being as follows: temperature equal to $400^{\circ} \mathrm{C}$, ultrasound with the frequency of $28 \mathrm{kHz}, \mathrm{Fe}^{+2} / \mathrm{H}_{2} \mathrm{O}_{2} 0.05 \mathrm{~mol} / \mathrm{mol}, \mathrm{pH} 2.1$ in an aqueous medium and the reaction time of $15 \mathrm{~min}$ the sulfur content in diesel fuel decreased from $568.75 \mu \mathrm{g} / \mathrm{g}$ to $9.5 \mu \mathrm{g} / \mathrm{g}$.

A new method for producing diesel fuel with ultra-low sulfur by oxidative desulfurization by means of ultrasound was proposed by the authors in [55].

The example of benzothiophene being the model sulfurcontaining compound of fuel demonstrates the possibility of quantitative catalytic desulfurization with suitable oxidizing agents during several minutes. Catalytic oxidation and sonication followed by solvent extraction at normal temperature and pressure were used for diesel fuels with different sulfur content. The degree of removal of sulfur- containing compounds reached more than $99 \%$ under the conditions of short contact time.

The effect of the frequency and intensity of ultrasound in the process of oxidative desulfurization of diesel fuel in the presence of $\mathrm{H}_{2} \mathrm{O}_{2}$ and organic acid at $20^{\circ} \mathrm{C}$, a catalyst/fuel ratio of 0.05 , a stirring speed of $300 \mathrm{rpm}$, a reaction time of 15 min, an ultrasound frequency of $28 \mathrm{kHz}$, and the radiation intensity $0.408 \mathrm{~W} / \mathrm{cm}^{2}$ followed by 2-time solvent extraction (DMF) were studied.

The degree of removal of sulfur-containing compounds during extraction is 94.8 and $67.2 \%$ for ultrasonicated fuel and non-sonicated fuel, respectively [55].

It was shown in [20-24] that the process of catalytic oxidation of sulfur-containing organic compounds in hydrocarbon media is intensified under the action of ultrasound.

The use of ultrasonic treatment enables to increase the degree of desulfurization by 2-4 times in comparison with catalytic desulfurization without ultrasound, which implies a deeper desulfurization of hydrocarbons. The oxidized sulfurcontaining organic compounds resulting from such a sonocatalytic reaction are capable of irreversible transition into droplets of a reverse aqueous hydrocarbon emulsion formed in the ultrasound field.

An important advantage of technological processes with the use of ultrasound is the possibility of their implementation in devices of any structural materials, shape and volume, under the conditions of carrying out the processes in continuous mode at elevated temperature and pressure [60$62]$.

The use of ultrasound favours the intensification of mass transfer in a desulfurization reactor [23]. Cavitation, which occurs with processing the liquid phase by ultrasound, contributes to breaking the liquid droplets by making up the oxidizer/hydrocarbon system into submicron and nano-sized droplets. Such a decrease in the diameter of the droplets contributes to the reaction that takes place at the interface, and enables to avoid the application of a phase transfer catalyst.

Table 1 shows some methods for the desulfurization of diesel fuel with and without ultrasonic treatment and shows the efficiency of ultrasonic treatment [23]. As it is seen from Table 1, the ultrasonic processing of the diesel fraction intensifies the desulfurization in all cases of ultrasound application. Thus, the degree of sulfur extraction does not exceed $66 \%$ per 2.5 hours with the oxidative desulfurization of the diesel fraction. The use of ultrasonic treatment with oxidative desulfurization of diesel fuel can increase the degree of sulfur removal up to $99 \%$ in a few minutes with the yield of purified fuel equal to $87 \%$.

Additionally, Table 1 shows that ultrasonic treatment of the diesel fraction in the presence of an aqueous solution of hydrogen peroxide and a quaternary ammonium salt as an interfacial catalyst reduces the sulfur content in the fuel to less than $0.25 \%$, i.e. desulfurization efficiency of the above examples is the highest and is equal to $99.75 \%$ 
In all cases, the impact of ultrasound on diesel fuel or its mixture with oxidizing agents, catalysts, organic acids or aqueous medium leads to an increase in the particles reactivity in the mixture $[53,60,61]$.

TABLE I. COMPARISON OF THE EFFICIENCY OF DF DESULFURIZATION WITH AND WITHOUT ULTRASOUND TREATMENT

\begin{tabular}{|c|c|c|c|}
\hline 离 & 胥 & 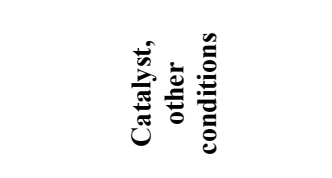 & 咅 \\
\hline \multirow{17}{*}{ 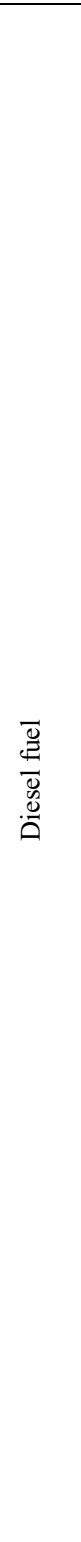 } & \multirow{2}{*}{$\begin{array}{l}\text { Without } \\
\text { oxydizing } \\
\text { agent }\end{array}$} & $\begin{array}{l}\text { Hydrotreating (temperature } \\
360^{\circ} \mathrm{C} \text {, pressure } 3 \mathrm{MPa} \text {, feed } \\
\text { space velocity }-3 \mathrm{~h}^{-1} \text {, } \\
\text { without activation by } \\
\text { ultrasound }\end{array}$ & $96.4 \%$ \\
\hline & & $\begin{array}{l}\text { Hydrotreating (temperature } \\
360^{\circ} \mathrm{C} \text {, pressure } 3 \mathrm{MPa} \text {, feed } \\
\text { space velocity }-3 \mathrm{~h}^{-1} \text { ), } \\
\text { with pre-activation of raw } \\
\text { materials by ultrasound }\end{array}$ & $97.0 \%$ \\
\hline & \multirow{11}{*}{$\mathrm{H}_{2} \mathrm{O}_{2}$} & - & $66 \%$ (2.5 hours $)$ \\
\hline & & Acetic acid/Ultrasound & $97.4 \%$ \\
\hline & & Acetic acid/ $\mathrm{Na}_{2} \mathrm{WO}_{4}$ & $>90 \%$ \\
\hline & & $\begin{array}{l}\text { Organic acid / without } \\
\text { ultrasound }\end{array}$ & $67.2 \%$ \\
\hline & & Organic acid / ultrasound & $94.5 \%$ \\
\hline & & $\begin{array}{l}\text { Organic acid / Activated } \\
\text { carbon }\end{array}$ & $>95 \%$ \\
\hline & & $\begin{array}{c}\text { Quaternary ammonium salt / } \\
\text { ultrasound }\end{array}$ & up to $0.25 \%$ \\
\hline & & $\begin{array}{l}\text { Ammonium tungstate / } \\
\text { without ultrasound }\end{array}$ & $29.1 \%$ \\
\hline & & $\begin{array}{c}\text { Ammonium tungstate / with } \\
\text { ultrasound }\end{array}$ & $79.1 \%$ \\
\hline & & $\mathrm{Mo} / \mathrm{Al}_{2} \mathrm{O}_{3}$ & 97.8 \\
\hline & & $\mathrm{Fe}^{+2} /$ ultrasound & $\begin{array}{c}\text { from } 568.75 \text { to } 9.5 \\
\mathrm{mg} / \mathrm{g}\end{array}$ \\
\hline & $\begin{array}{l}\mathrm{H}_{2} \mathrm{O}_{2} / \\
\text { acetone }\end{array}$ & ultrasound & $75.28 \%$ \\
\hline & $\begin{array}{c}\mathrm{H}_{2} \mathrm{O}_{2} / \\
\text { alcohol } \\
\text { oxide } \\
\end{array}$ & $\mathrm{MnO}_{2} / \mathrm{Al}_{2} \mathrm{O}_{3}$ & $\begin{array}{l}\text { from } 500 \text { to } \\
1 \mathrm{ppm}\end{array}$ \\
\hline & $\begin{array}{c}\text { Tert- } \\
\text { butylhydro- } \\
\text { peroxide }\end{array}$ & $\mathrm{Fe}-\mathrm{MoO}_{3} / \mathrm{Al}_{2} \mathrm{O}_{3}$ & $\begin{array}{l}\text { from } 440 \text { to } 88 \\
\text { ppm }\end{array}$ \\
\hline & ozone & Submicron bubbles & $>69 \%$ \\
\hline
\end{tabular}

Evidence of unusually high efficiency of ultrasonic treatment is the fact that dibenzothiophene and other sulfurcontaining organic sulphides, which are the most persistent organic sulfur compounds in diesel fuels, are easily converted to the corresponding sulfones under relatively mild conditions of temperature and pressure and under ultrasonic treatment.
The increased polarity of sulfones compared to sulfides ensures their high degree of susceptibility to removal using traditional separation processes based on polarity. The advantage of ultrasonic treatment in the DF oxidative desulfurization is that the oxidation proceeds selectively with respect to the conversion of compounds containing sulfur. Notably, there are no changes in the components of diesel fuel that do not contain sulfur. Another advantage of the use of ultrasound in the DF desulfurization is that the transformation occurs in a very short period of time, that is, during the period significantly less than one hour, preferably within 10-20 minutes on average.

\section{CONCLUSION}

1. Intensification of diesel fuel desulfurization is achieved by using unconventional methods and ultrasonic treatment is the most effective of them.

2. Ultrasonic treatment of the diesel fraction in all cases of ultrasound application leads to the increase in the degree of sulfur removal from diesel fuel. Thus, the oxidative desulfurization of the diesel fraction with hydrogen peroxide leads to the situation when the degree of sulfur recovery does not exceed $66 \%$ during 2.5 hours. The use of ultrasonic treatment allows increasing the degree of sulfur removal to over $99 \%$ in a few minutes with a yield of purified fuel equal to $87 \%$.

3. The highest degree of sulfur removal to less than $0.25 \%$ of the mass is achieved by using ultrasonic treatment of the diesel fraction in the presence of an aqueous solution of hydrogen peroxide and a quaternary ammonium salt as a phase transfer catalyst. The efficiency of desulfurization is $99.75 \% \mathrm{wt}$.

4. Ultrasonic treatment of diesel fuels can serve as a logical addition to the large-capacity hydrotreating process, and can be used as an independent method of deep desulfurization.

\section{Acknowledgment}

The work was supported by the Ministry of Education and Science of the Russian Federation under the agreement 14.577.21.0209, the unique identifier of the agreement is RFMEFI57716X0209.

\section{References}

[1] L.Sh.Makhmudova, Kh.H. Akhmadov, J.VOL. Khadisova, Z.A Abdulmezhidova, A.A. Pimenov, P.E. Krasnikov, "Production of lowfouling diesel fuels at Russian refineries: status and prospects", Ros.him. g. (J. Ros. Chemical Society. DI Mendeleev), vol. LXI, No. 1, p. 3-25, 2017.

[2] N.V. Borzenkova, I.A. Veselova, VOL.N.Shekhovtsova, "Biochemical methods for the desulfurization of hydrocarbons", Advances in modern biology, vol. 133, No. 1, p. 63-80, 2013 
[3] G. Mohebali, A.S. Ball, B. Rasekh, A.Kaytash, "Biodesulfurization potential of a newly isolated bacterium, Gordoniaalkanivorans RIPI90A”, Enz. Microb. Technol, 2007, vol. 40, no. 4, pp. 578-584.

[4] Anisimov A.V., Tarakanova A.V. "Oxidative desulfurization of hydrocarbon raw materials", Russian Chemical Journal (ZHRHO named after D.I. Mendeleev), 2008, vol. 5.-no.4, pp. 32-40.

[5] S.A. Yashnik, A.V. Salnikov, M.A. Kerzhentsev, L.M. Khitsova, V.Yu., Malysheva, T.N.Teryayeva, Z.R. Ismagilov, "Oxidative desulfurization of diesel fuels: the effect of the nature of the organic sulfur compound on the change in the composition of the modified $\mathrm{Cu}-\mathrm{Zn}-\mathrm{Al}$ catalysvol", Bulletin of the Kuzbass State Technical University, 2014, no.5 (105), pp.96-101.

[6] M.S. Mullakaev, D.F Asylbaev, G. B. Wexler, D.A. Baranov, "Ultrasonic intensification of the process of catalytic oxidation of organic sulfur compounds of the diesel fraction", Equipment and technologies for the oil and gas complex, 2016, no.4, pp.38-41.

[7] P.E. Krasnikov, Kh.H. Akhmadova, L.Sh. Makhmudova, Z.T. Khadisova, Z.A. Abdulmezhidova, "Desulfurization of diesel fuels using non-hydrogen technologies", November 2-04, 2017 Russia, vol. 1, Grozny: FSBEI HE "GGNTU", 2017, pp.524-530. [Basic and applied research: problems and results. Materials of the I International Scientific and Practical Conference dedicated to the 100th anniversary of them. Acad. Md Millionshchikov, 2017]

[8] Z,Ismagilov, S. Yashnik, M. Kerzhentsev, V. Parmon, A. Bourane, F.M. Al-Shahrani, A.A. Hajji, and O.R. Koseoglu, "Oxidative Desulfurization of Hydrocarbon Fuels", Catalysis Reviews: ScienceandEngineering, 2011, vol. 53, pp.199-255.

[9] E. B. Krivtsov, A. K.Golovko, "Kinetics of oxidative desulfurization of diesel fractions and theft of mixtures of hydrogen peroxide - formic acid", Petrochemistry, 2014, vol. 54, no.1, pp.52-58.

[10] E.V. Rakhmanov, D. Jinyuan, O.A. Fedorova, A.V. Tarakanova, A.V. Anisimov, "Oxidative desulfurization of diesel fuels in the presence of crown ethers and transition metal percomplexes", Chemical technology, 2011, no.1, pp.31-35.

[11] A.Kh. Sharipov, V.R. Nigmatullin, "Oxidative Desulfurization of Diesel Fuel (Review)", Neftekhimiya, 2005, vol. 45, no. 6, pp.403-410.

[12] A.Kh. Sharipov, "Preparation of organosulfur compounds from natural hydrocarbons (review)", Petrochemistry,2004, vol.44, no. 1, p.3-10.

[13] V.A. Budnik, T. M. Garifullin, V.V. Zolnikov, "Catalytic oxidation of distillate fractions in order to remove sulfur compounds", Oil refining and petrochemistry. Scientific and technical achievements and best practices, 2010, no. 3, pp. 33-37.

[14] E.V. Fedorova, A.V. Anisimov, "Oxidation of organic sulfur compounds in the presence of vanadium peroxo complexes (review)", Petrochemistry, 2003, vol. 43, no. 4, pp.243-251.

[15] Vishnetskaya M.V., Vakhrushin P.A. Oxidative desulfurization of diesel fuel on vanadium-molybdenum catalysts // Works of the Russian State University of Oil and Gas. THEM. Gubkin. -2011. - no. 3. - pp. 69-77.

[16] Kuzhaeva A.A., Kapralov D.A., Zainutdinov K.R. Non-traditional methods of sulfur removal in the oils of Tatarstan // "Scientific and educational space: new discoveries", Collection of scientific papers based on the materials of the I International Scientific and Practical Youth Conference, pp.58-61, 2017.

[17] A.G. Akhmadullina, R.M. Akhmadullin, "On New Developments and Implementations in the Field of Desulfurization of Hydrocarbons", Chemistry and Technology of Fuels and Oils, No. 6, pp.3-8, 2008.

[18] V.G. Rassadin, O.V. Durov, G.G. Vasiliev, N.G. Gavrilov, O. Yu. Shpygin, N.M. Likhterova, "Russian environmentally friendly diesel fuels of the European level of quality", Chemistry and technology of fuels and oils, No. 1, pp.3-9, 2007.

[19] N.M., Likhterova V.V., Lunin V.N., Torkhovsky V.K., Frantsuzov O.I. Kirillova, "Chemical activation of diesel fractions with ozone for the hydrotreating process", Petrochemistry, vol.45, No. 1, pp. 3-14, 2005.

[20] A.V. Kameshkov, A.A. Gaile, "Production of Diesel Fuels with Improved Low-Temperature Properties", Proceedings of the Svol. Petersburg State Technological Institute (Technical University), No. 29 (55), pp.49-60, 2015.

[21] M.S. Mullakaev, V.O. Abramov, G.B. Weksler, "Ultrasonic equipment in the processes of oil extraction and refining, purification of oil- contaminated waters and soils Part 1", Chemical Engineering, No. 10, pp. 39-43, 2012.

[22] M.S. Mullakaev, V.O. Abramov, G.B. Weksler, "Ultrasonic equipment in the processes of oil production and refining, purification of oilcontaminated water and soils. Part 2, Chemical Engineering, No. 11, pp. 34-38, 2012.

[23] A.V. Stavitskaya, "Development of methods for the oxidative modification of oil and products of its processing", Ph.D. thesis in Engineering Science. Mocow: Russian State University of Oil and Gas named after IM. Gubkina, p. 135, 2015.

[24] E.S. Gridneva, "Desulfurization of petroleum products under the action of ultrasound", Extended abtract of Ph.D. Moscow, p. 26, 2010.

[25] V.N. Khmelev, S.S. Khmelev, G.A. Bobrova, K.A. Karzakova, "Improving the Efficiency of Ultrasonic Cavitational Treatment of Petroleum Products", U-Sonic.Ru, Laboratory of Acoustic Processes and Apparatus BTI Alt GTU, Center for Ultrasonic Technologies.

[26] A.I. Nesterenko, Yu.S. Berlizy, "The possibility of cracking hydrocarbons under the action of cavitation. Quantitative Assessment, Chemistry and Technology of Fuels and Oils, No. 6, pp.43-44, 2007.

[27] A.I. Nesterenko, Yu.S. Berlizi, "On the use of the cavitation phenomenon for the cracking of hydrocarbons," Chemistry and Technology of Fuels and Oils, No. 4, p. 41-43, 2008.

[28] B.I. Bakhtin et al., "Low-temperature cracking of hydrocarbons in cavitation ultrasonic fields. (Beginning) ", World of petroleum products. Bulletin of Oil Companies, No. 6, p. 14-19, 2009.

[29] B.I. Bakhtin et al., "Low-temperature cracking of hydrocarbons in cavitation ultrasonic fields. (End) ", World of petroleum products. Bulletin of Oil Companies, No. 7-8, p. 52-58, 2009.

[30] D.O. Sidorenko, N.K. Zaitsev, S.V. Meshcheryakov, "Approaches to the separation of refinery sludge. Methods of chemical analysis of sludge and oil residues ", Environmental Protection in the Oil and Gas Complex, No. 1, pp.24-28, 2010.

[31] V.I. Ivannikov, "Cavitation and prospects for its use in the oil and gas industry", Construction of oil and gas wells onshore and offshore, no. 3, 2010.

[32] M.A. Promtov, "Cavitational technology for improving the quality of hydrocarbon fuels", Chemical and petroleum engineering, No. 2, pp. 6-8, 2000.

[33] S.S.Khmelev, V.N. Khmelev, D.S. Abramenko, S.N. Tsyanok, "Effectiveness increase of Ultrasonic Cavitational Processing of Viscous Liquid Media”, pp. 262-265, 2009 [Proceedings of $10^{\text {th }}$ International Workshops and Tutorials on Electron Devices and Materials, Novosibirsk, NSTU,.2009].

[34] V.V. Khmelev, G.V. Leonov, R.V. Barsukov, S.N. Tsyganok, A.V. Shalunov, Ultrasonic multifunctional and specialized devices for intensification of technological processes in industry, agriculture and household, Alvol. state tech. Univ, BTI. Biysk, Publishing House: Alvol. state tech. University, 2007, p. 400

[35] M.S. Mullakaev, "Ultrasonic intensification of technological processes for the extraction of oil refining, the purification of oil-polluted waters and soils", the thesis for the degree of Doctor. technical science, Moscow, .p. 212, 2011.

[36] M.S. Mullakaev, D.F. Asylbaev, G.B. Oganyan, V.O. Abramov, A.E. Gekhman, "Ultrasonic intensification of the catalytic oxidation process of mercaptans", Refining and Petrochemicals, No. 9, pp. 39-41, 2010.

[37] U.S. Patent No. 6,500,219. Continuous process for W. Gunnerman. Publication No. US 6,500,219 Bl, publ. on 31-Dec-2002.

[38] US Patent No. 6402939, Application No. 676260. Oxidative Desulfurization of Fussil Fuels, Mei Hai, Lu Steve Hung-Mou; Decl.28.09.2000; publ. 06.11.2002

[39] P.P. Vezirov, I.R. Telyashev, A.R. Davletshin, VOL.G. Biktimirov, E.G. Telyashev, "The Effect of Ultrasound on the Chemical and Fractional Composition of Oil Residues", Proceedings of the Novo-Ufimsky Refinery, Moscow: TsNIITEneftekhim, vol. 2, pp. 121-125, 1996.

[40] E.N. Mokry, V.L Starchevsky, Ultrasound in the process of oxidation of organic compounds, Lviv: Vishshash: Publishing House Lviv, 1987, p.118 
[41] G.A. Kardashev, Physical Methods of Intensification of Chemical Technology Processes. Moscow: Chemistry, 1990, p. 208.

[42] B.G. Novitsky, Application of acoustic oscillations in chemicaltechnological processes, Moscow: Chemistry, 1983, p.192.

[43] R.Sh. Mufazalov, I.G. Arslanov, R.N. Gimaev, R.K. Zaripov, Acoustic technology in the petrochemical industry, Kazan, Publishing House "Print House", 2001, p. 152

[44] A.K. Kurochkin, "Investigation of the effect of ultrasound on the intensification of certain oil technological processes," Dis. Cand. those. Of science Ufa, p.163, 1981.

[45] V.V. Krymsky, V.A. Fedotov, N.V. Plotnikova, "Sulfur Purification of Petroleum Products", In Proceedings,. Moscow, 3-7 dec. 2001, Vol. 2, pp. 65-67, 2001 [International Forum on Problems of Science, Technology and Education, 2001].

[46] Patent of the Russian Federation no.2003112227, IPC 7 C10G27 / 12, C10G32 / 00, B01L9 / 10. Method of oxidative desulfurization of fossil fuels using ultrasound / En Te Fu, Mei Hai, Lou Steve Hung-Mou no.2003112227 / 04; declare 09/24/2001; publ. 10.10.2004.

[47] H.Mei, B.W. Mei, VOL.F. Yen, "Fuel", vol.82, no.4, pp. 405-414, 2003.

[48] Patent of the Russian Federation No. 2235754. Method for the oxidative desulfurization of fossil fuels using ultrasound. JE Te Fu (US), MEI Hai (US), LU Steve Hung-Mou (US). Publ. 2001.09. 24

[49] M.W. Wan, T.F. Yen, “Appl. Fuel 2003”, Catal. A.: General,.vol. 319 , pp. 237-245, 2007.

[50] US Patent No. 6,429,239; Application No. 6,76260. Oxidative desulfurization of fossil fuels with ultrasound. Yen The Fu, Mei Hai, Lu Steve Hung-Mou; declare September 28, 2000; published 11/06/2002.

[51] "Desulphurization of Diesel Fuel", Petrol. Process and Petrochem, vol.37, No. 2, pp.30-33, 2006
[52] Hai Mei, B.W Mei, Teh Fu Yen, «A new method for obtaining ultra-low sulfur diesel fuel via ultrasound assisted oxidative desulfurization», «Fuel », vol. 82, no. 4, pp. 405-414, 2003.

[53] Patent of the Russian Federation No. 2003112227, IPC 7 C10G27 / 12 C10G32 / 00, B01L9 / 10. Method of oxidative desulfurization of fossil fuels using ultrasound / En Te Fu, Mei Hai, Lou Steve Hung-Mou no.2003112227 / 04; declare 09/24/2001; publ. 10.10.2004

[54] Patent No. 482,841, 1992.

[55] F.M Collins, A.R. Lusy, C Sharp, “J. Molec.”, Catal. A: Chem., vol. 117, pp. 397-403, 1997.

[56] Y.Q. Yongchuan Dai, "An oxidative desulfurization method using ultrasound", Fenton's reagent for obtaining low and or ultra-low sulfer diesel fuel, Fuel Processing Technology, vol. 89, no. 10,pp. 341-342, 2008.

[57] Patent of the Russian Federation no.2003112227, IPC 7 C10G27 / 12, C10G32 / 00, B01L9 / 10. Method for the oxidative desulfurization of fossil fuels using ultrasound / En Te Fu, Mei Hai, Lou Steve Hung-Mou - no.2003112227 / 04; declare 09/24/2001; publ. 10.10.2004.

[58] US Patent No. 6402939, Application No. 676260. Oxidative desulfurization of fossil fuels with ultrasound. Yen The Fu, Mei Hai, Lu Steve Hung-Mou; declare September 28, 2000; publ.11.06.2002.

[59] V.Meille, E. Shulz, M.Lemaire, M. Vrinat, “Appl. Catal”, A:General, vol. 187, no. 2, pp. 179-186, 1999.

[60] J.m.Campos-Martin [et al.], "Oxidative processes of desulfurization of liquid fuels", Journal of Chemical Technology \& Biotechnology, vol. 85 , no. 7 , pp. $879-890,2010$

[61] Y. T. Fu, M. Hai, L. S. Hung-Mou, Patent RF 2,235,754. Method for the oxidative desulfurization of fossil fuels using ultrasoun, stated 09. 04 2001. 